\title{
REAL-TIME WATER QUALITY MONITORING OF AN ARTIFICIAL LAKE USING A PORTABLE, AFFORDABLE, SIMPLE, ARDUINO- BASED OPEN SOURCE SENSOR
}

\author{
Murat Gökhan Eskin ${ }^{1}$, Milad Torabfam ${ }^{1}$, Elefteria Psillakis ${ }^{2}$, Alessandra Cincinelli ${ }^{3}$, \\ Hasan Kurt ${ }^{4 *}$, Meral Yüce ${ }^{5^{*}}$ \\ ${ }^{1}$ Sabanci University, Faculty of Engineering and Natural Sciences, 34956, Tuzla, Istanbul, Turkey \\ ${ }^{2}$ Technical University of Crete, School of Environmental Engineering, GR-73100, Chania, Greece \\ ${ }^{3}$ University of Florence, Department of Chemistry "Ugo Schiff", 50019, Florence, Italy \\ ${ }^{4}$ Istanbul Medipol University, School of Engineering and Natural Sciences, 34810, Beykoz, Istanbul, Turkey \\ ${ }^{5}$ Sabanci University SUNUM Nanotechnology Research and Application Centre, 34956, Tuzla, Istanbul, Turkey \\ *E-mail of corresponding authors: meralyuce@sabanciuniv.edu, hasankurt@medipol.edu.tr
}

\begin{abstract}
Water quality assessment is vital to identify existing problems and any changes that emerge in water sources over a period of time. Conventional water quality monitoring systems remain to be limited to on-site sample collection and further analysis in environmental laboratories. The progress in Arduino-based low-cost and open-source hardware has paved the way for the development of low-cost, portable, and on-site measuring platforms. In this work, we have assembled an Arduino-based open-source water testing platform out of commercially available sensors and controllers. The water testing system was powered by a $9 \mathrm{~V}$ battery and had the capability of measuring water turbidity, acidity, and temperature on-site in real-time. The calibration and validation studies were carried out to assess the measurement capabilities of turbidity and pH sensors in the lab using calibration samples and UV-Vis-NIR absorption spectroscopy. The water quality platform was tested in an artificial lake that is located at Sabanci University Campus (Istanbul, Turkey), which serves as a reservoir for treated wastewaters and rainwater. Untreated wastewater samples were collected from the wastewater treatment station of the university for comparison. The measurements performed on several locations along the coast of the artificial lake were also validated in the laboratory. The water testing platform showed significant potential for miniaturization and portability of such analytical platforms for on-site environmental monitoring.
\end{abstract}

Keywords: Open source, water quality, turbidity, Arduino, water treatment

\begin{tabular}{c}
\hline Received: 29.04 .2019$. / Accepted: 11.06.2019. \\
Published online: 16.07 .2019$. \\
\hline
\end{tabular}

Original scientific paper

\section{INTRODUCTION}

Industrialization and urbanization resulted in changes on surface and groundwater quality. 844 million people do not have access to even a primary drinking water service (World Health Organization-WHO and The United Nations Children's Fund-UNICEF 2017). The term wastewater is used for any water that has been influenced by human use. In other words, wastewater can be defined as a by-product of domestic, agricultural, commercial, as well as industrial activities (Tilley et al. 2014). Thus, the composition and properties of wastewater differ widely depending on the source. It mostly consists of chemical or physical pollutants ranging from heavy metals, organic and inorganic particles to toxins. Furthermore, biological contaminants of wastewater are bacteria, viruses, and protozoa (Andersson et al. 2016). About 1.5 million children under the age of five die due to diarrhea each year (UNICEF). The fresh water, which is only 3\% of the Earth's natural water resources has been contaminated gradually with increased human activity (Kumari 2018). As a result, the assessment of the water quality for drinking or agricultural purposes is imperative (Carpenter et al. 1998). However, the advanced analytical methods to measure the water quality, e.g., atomic absorption spectrophotometry, gas chromatography or flame photometry, are either expensive (United Nations Environmental Programme-UNEP and WHO 1996; Kirchner et al. 2004) or time-consuming that requires sending water samples to a laboratory for analysis (Oelen et al. 2018). Furthermore, fast-decaying pollutants such as 1,4-dioxane make the on-site measurements more credible and valuable.

Turbidity, temperature, and $\mathrm{pH}$ are essential parameters to evaluate water quality. Turbidity is a measure of fluid clarity or cloudiness which is caused by the microscopic plants, animals, or solids suspended in that fluid. High turbidity levels may be an indicator of the existence of pathogens such as viruses, parasites, bacteria, or chemical contamination (Mann et al. 2007). Water turbidity can be measured by using turbidity sensors that quantify the light transmittance and scattering caused by the suspended particles in the water when an incident light beam is sent. The unit for turbidity is NTU (nephelometric turbidity unit).

Temperature affects the metabolism, reproduction, and emergence of most of the organisms that live in water since they are adapted to live in a narrow temperature range. The temperature of the water may also play a 
significant role in an increased toxic activity, which is caused by pollutants (Cairns et al.1975). Furthermore, less oxygen can be dissolved in warmer water. The temperature can be measured by using temperature sensors composed of thermocouples with waterproof housing.

The acidity is expressed in terms of the number of hydrogen ions, and the $\mathrm{pH}$ is a measure of free hydrogen ion concentration in the logarithmic scale. The $\mathrm{pH}$ of water decreases as it becomes more acidic $(\mathrm{pH}<7)$. Pure water has a $\mathrm{pH}$ of around 7, which means it is neutral. The existence of chemicals in the water affect the $\mathrm{pH}$, which makes the $\mathrm{pH}$ of water an essential indicator of water quality. There are three different ways to measure $\mathrm{pH}$ (UNEP and WHO 1996). The first two are using $\mathrm{pH}$ indicator paper or indicator liquid, which both involve subjective assessment of the color by the human eye. The third method is to use an electrometric $\mathrm{pH}$ measurement, which consists in measuring the electrical potential difference between the $\mathrm{H}^{+}$sensitive glass electrode and the reference electrode. This technique is accurate, fast, and can be performed in situ.

In the past, these types of measurements were done by dated equipment in the lab. However, free and opensource software (FOSS) is an available device, nowadays, that can pave the way for important measurements. FOSS is defined as computer software available in an open-source form, and that can be utilized, modified, and redistributed without any restriction (Milanovic et al. 2018). These days, FOSS is becoming the norm in software evolution, with a variety of applications, including science and education (Pearce J. 2013), medicine (Lang 2011), engineering and nanotechnology (Pearce 2013). Creating both software and hardware is feasible by a transparent system represented by FOSS and improving open-source hardware results in a significant cost reduction, enabling the state of the art scientific tools available all over the world (Pearce et al. 2010). According to the literature, there are various open-source “do-it-yourself” devices, including: a potentiostat (Arevalo-Ramirez et al. 2017), syringe pump (Wijnen et al. 2014), a colorimeter (Anzalone et al. 2013), pH-meter (Milanovic et al. 2018) which can be provided by scientists with low costs. However, to our knowledge, the open-source device for measuring Turbidity, $\mathrm{pH}$, and Temperature values has been provided in a notably smaller range (Garbacz et al. 2013). Considering that the average cost of commercially accessible measuring units and software comes at huge costs, the cost can be considered as a limiting factor for providing the abovementioned device in the developing world. To improve the assays in which these measurements are needed, the affordable open-source "Open Turbidity-pH-Temperature Control" software has been designed by using low-priced laboratory equipment.

Using open-source hardware and software is one way to decrease the cost while still acquiring reliable assessment data. As a result, alternative methods which involve practical and cheaper testing platforms with multiple sensors were reported (Rao et al. 2013; Kelley et al. 2014; Wijnen et al. 2014; Jin et al. 2018; Milanovic et al. 2018; Oelen et al. 2018; Parra et al. 2018). Rao et al. (2013) designed a continuous low-cost water quality monitoring system using an Arduino Mega 2560 to control six different sensors: temperature, light, $\mathrm{pH}$, conductivity, dissolved oxygen, and oxidation-reduction potential. Kelley et al. (2014) used a $20 \mathrm{MHz}$, 8-bit microprocessor, which was programmed in the C-based Arduino language to measure turbidity. They 3D-printed the housing and produced their turbidity sensor in-house. Wijnen et al. (2014) built an open source, mobile water quality testing platform to measure the turbidity that utilizes both colorimetry and nephelometry. The data processing was performed by an Arduino Fio board. Lopez-Ruiz et al. (2014) determined the nitrite concentration and $\mathrm{pH}$ of water samples by using a low-cost, paper-based microfluidic device and used a smartphone as the light source and an image processing computer. Milanovic et al. (2018) constructed a pH-stat device by using free and open source software and inexpensive hardware such as Arduino Nano and 3D-printed parts. Oelen et al. (2018) controlled four different sensors with an Arduino board: a TDS (total dissolved solids), $\mathrm{pH}$, turbidity, and temperature sensors. The resulting device can be used for monitoring the water quality continuously and autonomously. Moreover, Jin et al. (2018) built the inexpensive hardware for $\mathrm{pH}$ determination on a breadboard. They used an Arduino Nano to evaluate the $\mathrm{pH}$ and communicate the data over Bluetooth, utilizing a smartphone as a monitor. In this work, we have assembled an Arduino-based open-source water testing platform out of commercially available sensors and controllers.

\section{METHODOLOGY}

\subsection{Design}

All the components were assembled on a breadboard. An Arduino Nano microprocessor was used to control and monitor the sensors. The turbidity sensor (Stock Keeping Unit (SKU): SEN0189 from dfrobot.com) was composed of a light transmitter and a receiver, which comes with an amplifier. The signal pin was connected to the analog A0 input of the Arduino board. The DS18B20 temperature sensor (SKU: DFR0198 from dfrobot.com) was a 1-wire digital temperature sensor which has a unique 64-bit ID burned at the factory that allows connecting multiple temperature sensors to the same pin.

The $\mathrm{pH}$ sensor (SKU: SEN0161 from dfrobot.com) included a glass bulb with $\mathrm{H}^{+}$sensitive coating covering the electrode. The $\mathrm{pH}$ sensor was connected to a circuit board via a BNC (Bayonet Neill-Concelman) cable and the connection to the analog A1 input of the Arduino board was through this circuit board.

The HC-05 Bluetooth SPP (serial port protocol) module transmitted and received the serial data through its digital pins called as Transmit (TX, digital pin 1) and Receive (RX, digital pin 0) respectively. The RX pin was 
connected to the digital D11 input of the Arduino. The RX line was connected to the digital D10 input after a voltage divider employing a $2.2 \mathrm{k}$ and a $1 \mathrm{k}$ resistor coming from the $5 \mathrm{~V}$ line of the Arduino.

The Arduino was powered by a $9 \mathrm{~V}$ battery. All the components are fed from the $5 \mathrm{~V}$ line of the Arduino. An illustration of the components used in the device and the real photograph of the device are shown in Figure 1.
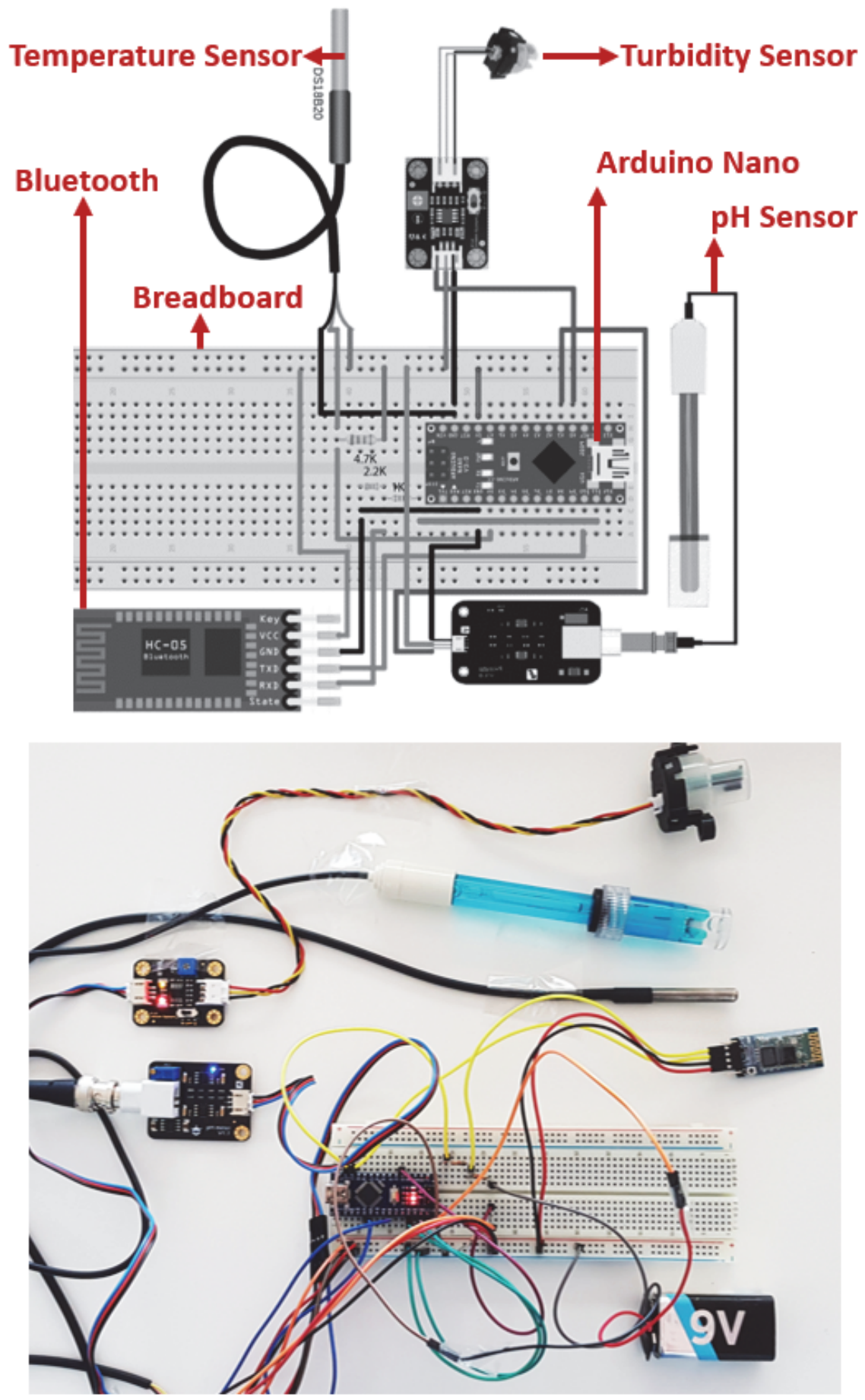

Figure 1. An illustration of the components used in the device (Top) and the actual open source hardware (Bottom)

\subsection{Calibration and Validation}

The turbidity sensor consists of and near-infrared light emitting diode (LED) and photodiode sensor. Depending on the turbidity of the solution, the amount of light reaching from the LED to photodiode decreases leading to decrease in the photodiode voltage with respect to the unobstructed transmission of emitted light. The turbidity sensor was calibrated using pure water as 0 NTU, calibration standarts of 400 and 1000 NTU (Figure 2). 


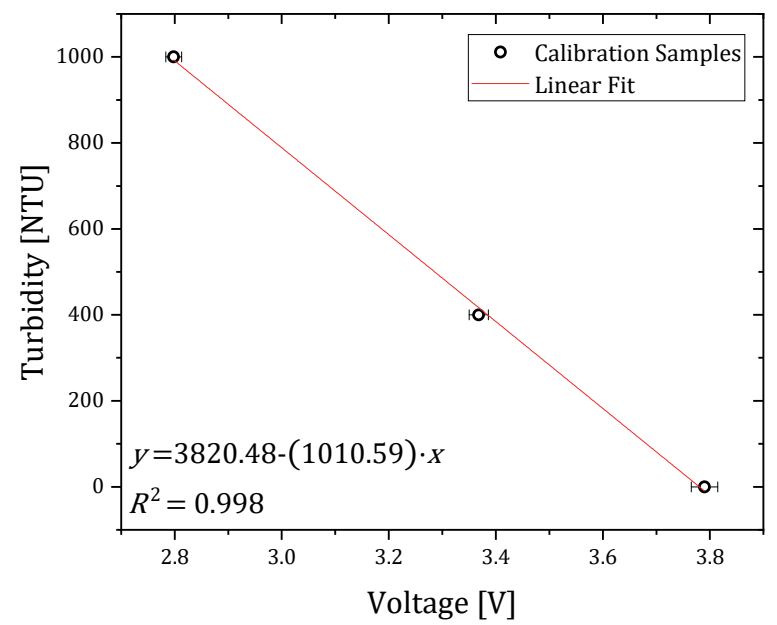

Figure 2. Turbidity calibration samples vs turbidity sensor voltage

The linear fit performed on the NTU values vs voltage readings yielded the following calibration equation:

$$
\text { Turbidity value (in NTU) }=-1010.59 \times V+3820.487
$$

where $V$ is the voltage reading from the liquid whose turbidity is to be measured.

For the validation of turbidity measurements, the samples from four designated sites and treatment center as well as turbidity calibration samples of 400 NTU and 1000 NTU were also analyzed using UV-Vis-NIR spectroscopy. The absorbance of samples was recorded using Cary 5000 UV-Vis-NIR spectrophotometer. The wavelength of $750 \mathrm{~nm}$ was selected to bypass visible absorbance of particles in the samples. Thus, the absorbance values are highly depended on the scattering of the particles in the samples. The correlation of turbidity levels and absorbance at wavelength a of $750 \mathrm{~nm}$ were shown in Figure 3. In line with measured turbidity levels, absorbance at wavelength a of $750 \mathrm{~nm}$ stayed below 0.16 for Site 1 and Site 2 and rose to $0.24-0.28$ for Sites 3, 4 and treated samples. Meanwhile, the untreated sample showed a high level of absorbance of 2.918 as expected.

The $\mathrm{pH}$ sensor was calibrated using three different buffer solutions with $\mathrm{pH}$ values of 4.01, 7.00, and 10.01. After operating the $\mathrm{pH}$ sensor over the Arduino Nano through the circuit board that came with the $\mathrm{pH}$ sensor, the potentiometer on the circuit board was adjusted to match the serial monitor reading to the correct $\mathrm{pH}$ value of that buffer solution. This calibration was performed for three times for an optimized setting. For validation of the $\mathrm{pH}$ sensor, all collected samples and calibration standards were also measured using Hanna HI2210-01 benchtop pH meter. The validation of the $\mathrm{pH}$ sensor readings were correlated with the benchtop readings in laboratory.

The temperature sensor does not have to be calibrated when the proper Arduino library (Dallas Temperature) was pre-calibrated. The source codes that control each of the sensors can be found online.
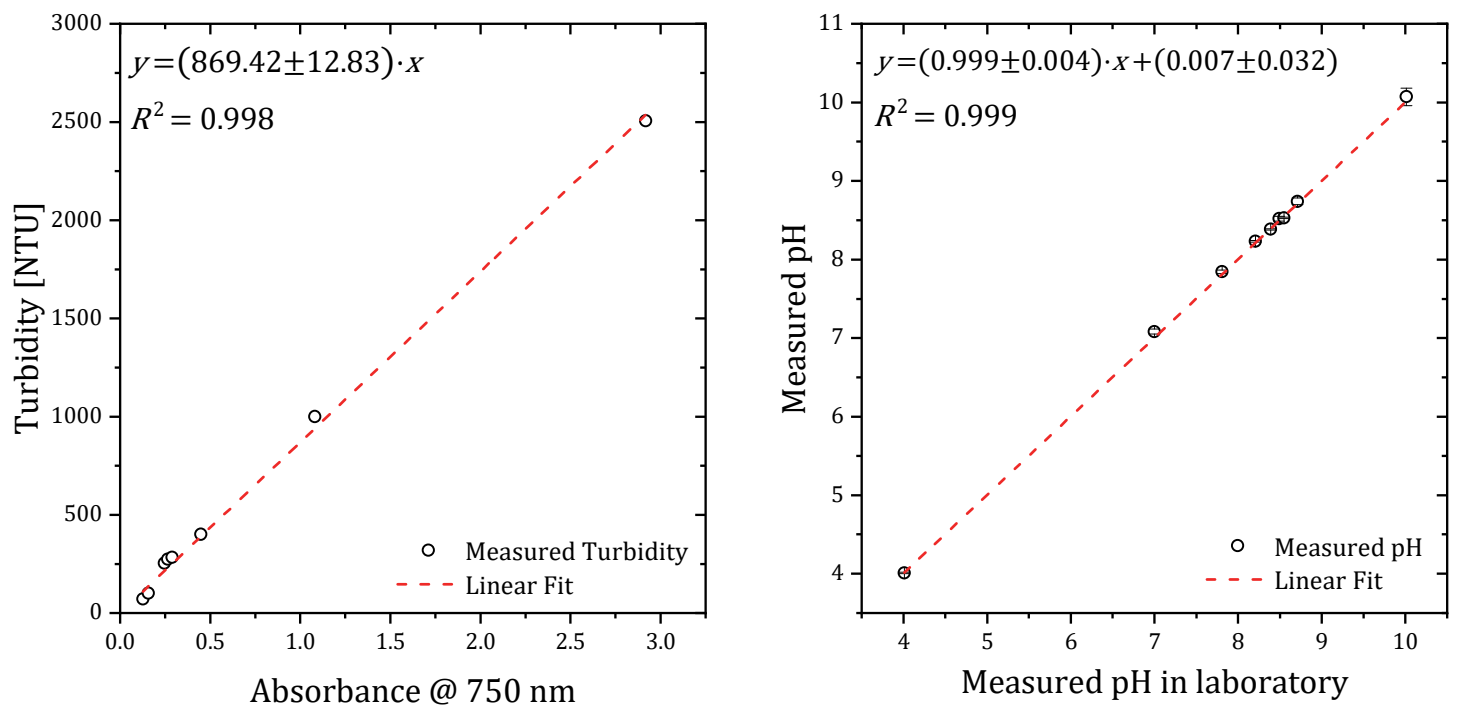

Figure 3. Validation of turbidity readings with absorbance measurements at a wavelength of $750 \mathrm{~nm}$ (left) for samples from 4 designated sites, untreated water waste, treated water, and $400 \& 1000$ NTU calibration standards and pH measurements of samples from 4 designated sites, untreated water waste, treated water and standard $\mathrm{pH}$ calibration solutions (pH 4.01, pH 7 and pH 10) (right). 


\section{RESULTS AND DISCUSSION}

The Sabanci University has an artificial lake which was transformed from a 7-8 meters deep amorphous pit in the foundation of the university. While transforming the pit into an artificial lake, the bottom of the pit was levelled and deposited with clay and gravel. The artificial lake was filled with rain, stormwater drains of the campus buildings, and treated sewage. The lake remains to be used for irrigation reservoir for plants in the campus. Upon the arrival of fish eggs by seagulls, the artificial lake formed a natural fauna.

We utilized an open-source, cost-effective and portable water quality testing platform that can measure the turbidity, temperature, and $\mathrm{pH}$ of the water in real time, and transfer the results to smartphones over a Bluetooth module, eliminating the need for a dedicated monitoring device and expert. The samples were collected from the artificial lake inside Sabanci University campus as well as untreated and treated water from Sabanci University Wastewater Treatment Plant. In this center, treated water is provided through some operations where the first step is pre-treatment, which consists of screening, equalization, and pumping station (Sabanci University 1999). This is followed by biological treatment, including sequencing batch reactor with blower-diffuser aeration. Next step is advanced treatment such as filtration. Following this, chlorine disinfection of the effluent is applied to the sample. Finally, sludge treatment is utilized by using a sludge dewatering system. In order to provide precise results, calibration is required. By performing this step, the device offers an accurate indication or output signal when it is installed.

The samples of the artificial lake were collected from 4 different sites along the coast of the lake, as shown in Figure 4. Site 1 was the small artificial waterfall which feeds the artificial lake. Site 4 was close to the waterways of water treatment station feeding into the artificial lake. We also collected samples from a water treatment center to assess the quality of untreated and treated water. The collected samples were also analyzed in the lab, as shown in Figure 5. Initial visual assessment, the treated and samples along the coast are highly transparent with a low level of large particles inside.

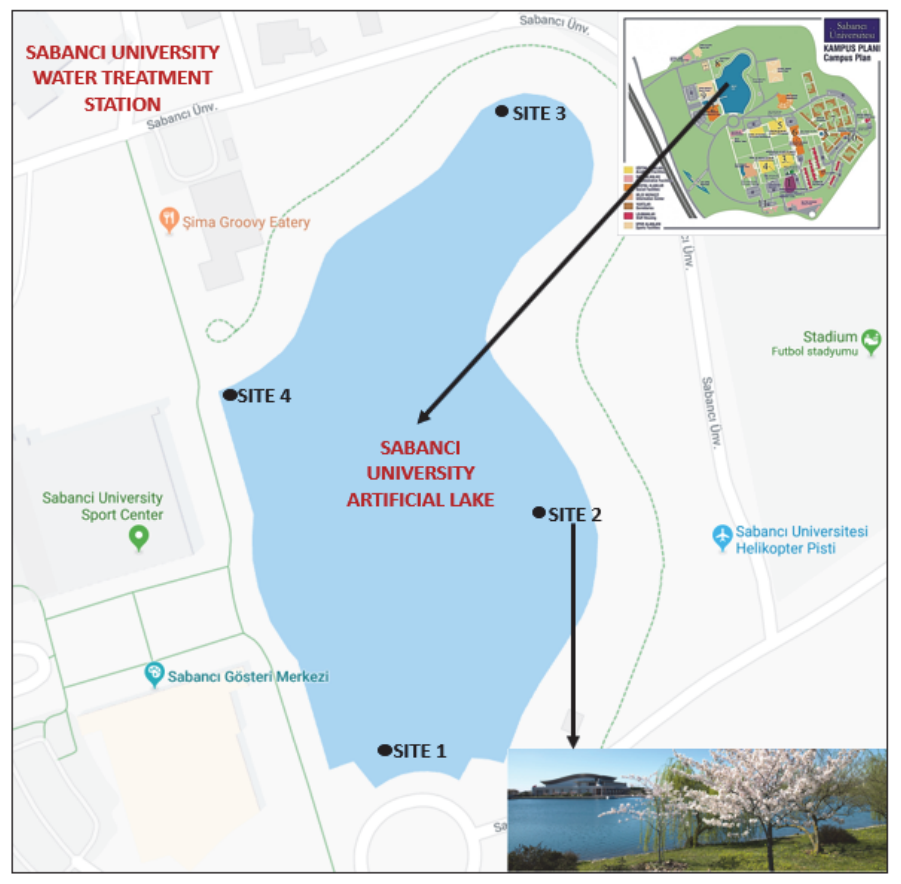

Figure 4. Sites where the samples are collected on the campus of Sabanci University
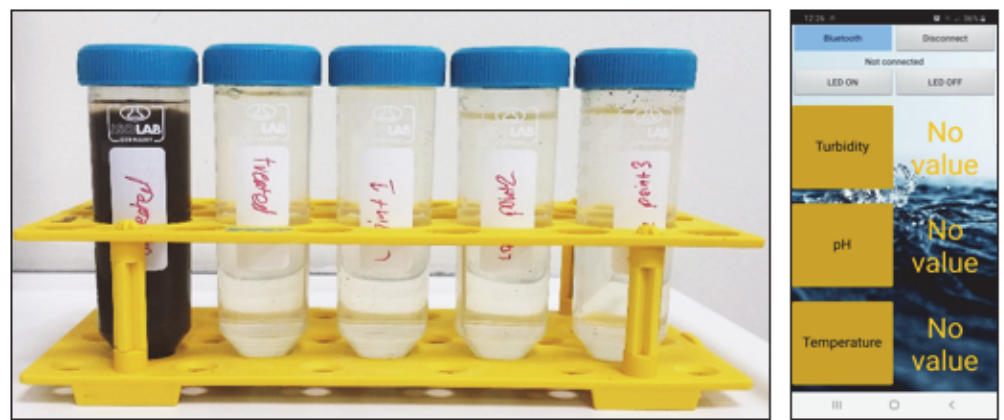

Figure 5. The samples collected from the designated sites for absorbance, and turbidity measurements (left), Android-based smartphone application interface (right). 
The on-site measurements showed that the turbidity levels were below $300 \mathrm{NTU}$ along the coast of the artificial lake and the treated water sample collected from the water treatment center, as shown in Figure 6. The untreated water sample was highly turbid, reaching around $2506 \mathrm{NTU}$, and the collected samples tended to sediment within minutes. Site 1 had an artificial waterfall, and Site 2 was placed close to the waterfall. The accelerated surface waves tend to push the large particulates to the north end of the shallow cost of the lake. Turbidity levels of Site 1 and 2 remained around 71 and 101 NTU, respectively. However, the shallow and considerable calmer Sites 3 and 4 had 253 and 273 NTU, respectively, and were close to the treated water turbidity level of 283 NTU. The samples mentioned above were also collected in falcon tubes for absorbance analysis.

The acidity of the artificial lake was measured as higher than a $\mathrm{pH}$ of 8 . The $\mathrm{pH}$ levels were increased as the collection site were further away from the artificial lake and closer to the treatment channel connected to the lake. The $\mathrm{pH}$ level of 8.38 was measured on Site 1. Site 2 and 3 showed a slightly higher $\mathrm{pH}$ of 8.5 . Site 4 showed highly elevated levels of $\mathrm{pH}$ around 8.74. Meanwhile, the collected samples from untreated and treated water showed a $\mathrm{pH}$ level of 7.84 and 8.23 , respectively.
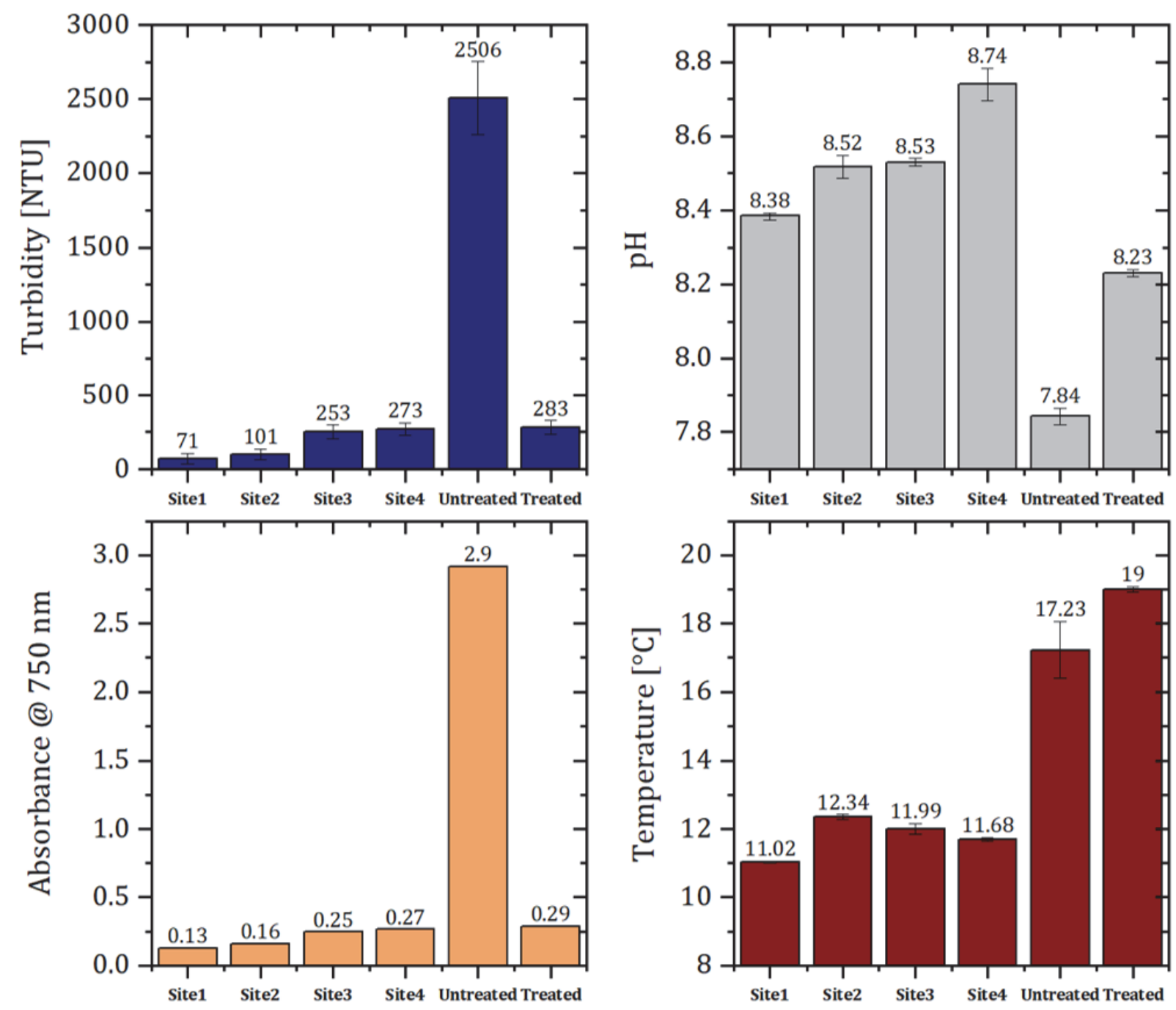

Figure 6. Graph of turbidity, $p H$, absorbance and temperature measurements from various sites on shores of the artificial lake, untreated, and treated samples from the water treatment center.

\section{CONCLUSIONS}

The low cost and widespread availability of open-source hardware enabled environmental scientists to exclude the use of high-cost analytical equipment and perform analyses on site. The presented on-site water pollution testing platform was used to monitor the water quality of an artificial lake that is feed with the treated wastewater. Noteworthy is the fact that instrument error is probable to occur due to various factors including environmental issues, electrical supply, the addition of excessive components to the output loop and process alteration. However, these errors can be minimized if not eliminated by applying a calibration procedure. An error can be defined as 
the dissimilarity between the indication and the actual amount of the measured parameter. To determine and rectify device errors, periodic calibrations were applied. The most stable probe is the temperature sensor due to the standard thermometer that has been used in our assay. Also, we obtained balanced and stable data for $\mathrm{pH}$ measurements. Unlike temperature and $\mathrm{pH}$ sensors, a significant deviation was observed in the turbidity sensor. This defect is related to the structure of the turbidity sensor suffering from waterproofing, although it was weak. On the other hand, the device is cost-effective and portable, promoting the development of robust software equipment which we are growingly reliant on.

This initial work and results act as stimuli for further studies on open-source on-site measurements systems. Future work may lead researchers to construct a remote-controlled model ship, which probes the water quality continuously along the artificial lake with integrated navigation. The growing repertoire of water quality monitoring with commercially available open-source sensors such as ammonia and dissolved oxygen would further improve the applicability of the proposed open-source sensing platform.

\section{ACKNOWLEDGMENTS}

The study was carried out in the frame of COST Action CA16215, "European network for the promotion of portable, affordable and simple analytical platforms". We thank Katrina Laganovska and Krisjanis Smits for the design for Arduino-based water testing platform and the informative workshop in Varazdin, Croatia. We would like to thank Andrew Campbell for the donation of open-source hardware used in this work.

\section{REFERENCES}

Andersson K, Rosemarin A, Lamizana B, Kvarnström E, Mcconville J, Seidu R, Dickin S, Trimmer C (2016) Sanitation, Wastewater Management and Sustainability: From Waste Disposal to Resource Management.

Anzalone GC, Glover AG, Pearce JM (2013) Open-Source Colorimeter. Sensors, 13:5338-5346.

Arevalo-Ramirez T, Castillo Torres C, Cela A, Espinoza-Montero P (2016) Low cost potentiostat: Criteria and considerations for its design and construction. Proceedings of the 2016 IEEE ANDESCON, ANDESCON 2016, doi:10.1109/ANDESCON.2016.7836211.

Cairns J, Heath AG and Parker BC (1975) The effects of temperature upon the toxicity of chemicals to aquatic organisms, Hydrobiologia, 47(1):135-171. doi: 10.1007/BF00036747.

Carpenter SR, Caraco NF, Correll DL, Howarth RW, Sharpley AN, Smith VH (1998) Nonpoint Pollution of Surface Waters with Phosphorus and Nitrogen, Ecological Applications, 8(3):559-568.

Garbacz G, Kołodziej B, Koziolek M, Weitschies W, Klein S (2013) An Automated System for Monitoring and Regulating the $\mathrm{pH}$ of Bicarbonate Buffers, AAPS PharmSciTech, 14(2):517-522. doi: 10.1208/s12249-0139933-5.

Jin, H., Qin Y, Pan S, Alam AU, Dong S, Ghosh R, Deen MJ (2018). Open-Source Low-Cost Wireless Potentiometric Instrument for $\mathrm{pH}$ Determination Experiments. Journal of Chemical Education, 95(2):326-330. https://doi.org/10.1021/acs.jchemed.7b00479

Pearce JM (2013) Open-Source Nanotechnology: Solutions to a Modern Intellectual Property Tragedy, Nano Today, 8(4):339-341.

Kelley CD, Krolick A, Brunner L, Burklund A, Kahn D, Ball WP, Weber-Shirk M (2014) An Affordable Open-Source Turbidimeter. Sensors 2014(14):7142-7155 doi: 10.3390/s140407142.

Kirchner JW, Feng X, Neal C, Robson AJ (2004) The fine structure of water-quality dynamics: the(highfrequency) wave of the future, Hydrological Processes, 18(7):1353-1359. doi: 10.1002/hyp.5537.

Kumari R (2018) Summing up water characteristics with software-analysed trophic interrelations in a pond., International Journal of Advanced Research, 6(12):952-955. doi: 10.21474/IJAR01/8221.

Lang T (2011) Advancing Global Health Research Through Digital Technology and Sharing Data, Science, 331(6018):714-717. doi: 10.1126/science.1199349.

López-Ruiz N, Curto V, Erenas M, Benito-Lopez F, Diamond D, Palma A, Capitan-Vallvey LF (2014) Smartphone-Based Simultaneous $\mathrm{pH}$ and Nitrite Colorimetric Determination for Paper Microfluidic Devices. Analytical chemistry. 86(19):9554-9562 doi:10.1021/ac5019205.

Mann AG, Tam CC, Higgins CD, Rodrigues LC (2007) The association between drinking water turbidity and gastrointestinal illness: a systematic review, BMC Public Health, 7(1):256. doi: 10.1186/1471-2458-7-256.

Milanovic J, Milanovic P, Kragic R, Kostic M (2018) "Do-It-Yourself" reliable pH-stat device by using opensource software, inexpensive hardware and available laboratory equipment. PLOS ONE. 13(3), pp. 1-18. doi: 10.1371/journal.pone.0193744.

Oelen A, Van Aart C \& De Boer V (2018) Measuring surface water quality using a low-cost sensor kit within the context of rural Africa. in Perspectives on ICT4D: Proceedings of the 5th International Symposium "Perspectives on ICT4D" co-located with 10th ACM Web Science Conference (WebSci'18). Amsterdam, the Netherlands, May 27, 2018.. vol. 2120, CEUR Workshop Proceedings, CEUR Workshop Proceedings, 5th International Symposium "Perspectives on ICT4D", P-ICT4D 2018, Amsterdam, Netherlands, May 27, 2018. 
Parra L, Sendra S, García L, Lloret J (2018) Design and Deployment of Low-Cost Sensors for Monitoring the Water Quality and Fish Behavior in Aquaculture Tanks during the Feeding Process. Sensors, 18(3):750. doi:10.3390/s18030750

Pearce, J, Morris Blair, C, Laciak, KJ, Andrews R, Amir N, Zelenika-Zovko I (2010). 3-D Printing of Open Source Appropriate Technologies for Self-Directed Sustainable Development. International Journal of Sustainable Development. 3(4):17-29. doi:10.5539/jsd.v3n4p17.

Pearce J. (2013) Open-Source Lab: How to Build Your Own Hardware and Reduce Research Costs, Elsevier LTD, Oxford.

Rao AS, Marshall S, Gubbi J, Palaniswami M, Sinnott RO, Pettigrovet V (2013) Design of low-cost autonomous water quality monitoring system. in International Conference on Advances in Computing, Communications and Informatics (ICACCI), 14-19. doi: 10.1109/ICACCI.2013.6637139.

Sabanci University (1999) Domestic Wastewater Composition, 90(262):41480. Available at: https://www.sabanciuniv.edu/en/green-campus.

Tilley E, Luthi C, Morel A, Zurbrügg C, Schertenleib R (2008) Compendium of Sanitation Systems and Technologies doi: SAN-12. UNICEF, W. (no date) Unicef Diarrhoea disease.

United Nations Environmental Programme and World Health Organization (1996) Water Quality Monitoring.

Wijnen B, Hunt EJ, Anzalone GC, Pearce JM (2014) Open-Source Syringe Pump Library. PLoS ONE 9(9): e107216. https://doi.org/10.1371/journal.pone.0107216

Wijnen B, Anzalone GC, Pearce JM (2014) Open-source mobile water quality testing platform, Journal of Water, Sanitation and Hygiene for Development, 4(3):532-537. doi: 10.2166/washdev.2014.137.

World Health Organization (WHO) and The United Nations Children's Fund (UNICEF) (2017) "Progress on Drinking Water, Sanitation and Hygiene: 2017 Update and SDG Baseline," World Health Organization, p. 66. doi: 10.1016/j.pnpbp.2017.06.016. 